2005-03-16

\title{
The Effects of Choice on Student Motivation and Physical Activity Behavior in Physical Education
}

Jillian Ward

Brigham Young University - Provo

Follow this and additional works at: https://scholarsarchive.byu.edu/etd

Part of the Exercise Science Commons

\section{BYU ScholarsArchive Citation}

Ward, Jillian, "The Effects of Choice on Student Motivation and Physical Activity Behavior in Physical Education" (2005). Theses and Dissertations. 265.

https://scholarsarchive.byu.edu/etd/265

This Thesis is brought to you for free and open access by BYU ScholarsArchive. It has been accepted for inclusion in Theses and Dissertations by an authorized administrator of BYU ScholarsArchive. For more information, please contact scholarsarchive@byu.edu, ellen_amatangelo@byu.edu. 
THE EFFECTS OF CHOICE ON STUDENT MOTIVATION AND PHYSICAL ACTIVITY BEHAVIOR IN PHYSICAL EDUCATION

by

Jillian Ward

A thesis submitted to the faculty of

Brigham Young University

in partial fulfillment of the requirements for the degree of

Master of Science

Department of Exercise Sciences

Brigham Young University

April 2005 
Copyright (C) 2005 Jillian Ward All Rights Reserved 
BRIGHAM YOUNG UNIVERSITY

GRADUATE COMMITTEE APPROVAL

of a thesis submitted by

Jillian Ward

This thesis has been read by each member of the following graduate committee and by majority vote has been found to be satisfactory.

Date

Date

Date
Carol Wilkinson, Chair

Susan D. Vincent

Keven A. Prusak 


\section{BRIGHAM YOUNG UNIVERSITY}

As chair of the candidate's graduate committee, I have read the thesis of Jillian Ward in its final form and have found that (1) its format, citations, and bibliographical style are consistent and acceptable and fulfill university and department style requirements; (2) its illustrative materials including figures, tables, and charts are in place; and (3) the final manuscript is satisfactory to the graduate committee and is ready for submission to the university library.

Date

Carol Wilkinson

Chair, Graduate Committee

Accepted for the Department

Ruel M. Barker

Chair, Department of Exercise Sciences

Accepted for the College

Gordon B. Lindsay, Associate Dean

College of Health and Human Performance 


\begin{abstract}
THE EFFECTS OF CHOICE ON STUDENT MOTIVATION AND PHYSICAL ACTIVITY BEHAVIOR IN PHYSICAL EDUCATION

\author{
Jillian Ward \\ Department of Exercise Sciences \\ Master of Science
}

Public school physical educators have the opportunity to help students understand the importance of engaging in regular physical activity in order to combat America's obesity problem. However, students are often unmotivated to participate in their physical education classes. Providing students with an autonomy supportive environment increases intrinsic motivation. Self-determination theory states that higher levels of intrinsic motivation should lead to an increase in behavior, or higher activity levels in a physical education class.

This study examined (a) the effects of increased autonomy on self-determination, and (b) the effects of increased autonomy on physical activity levels. Seventh and eighth grade girls $(\mathrm{n}=122)$ in four classes participated in two fitness units (one allowing choice of activities, the other no choice). The 14-item abridged Situational Motivation Scale (SIMS) was administered pre and post each unit. Pedometers were used to measure step 
counts during both units. Results of the SIMS data showed there was a significant difference in motivation between the trials for all students, and between the groups (pre and post) during the second unit. There was no significant difference in step counts for all students between Unit 1 and Unit 2, and no difference between groups. The results revealed that increased autonomy in activity selection increases student selfdetermination, and therefore, should be implemented into the physical education curriculum. To truly determine the relationship between increased autonomy and activity levels, students need to be in an environment where they can be responsible for their own behavior, and where they can choose how much effort they are willing to put into the activities they have chosen.

Keywords: autonomy, self-determination theory, physical activity levels, fitness 


\section{ACKNOWLEDGMENTS}

I would like to express my love and appreciation to my parents, Ralph and Ann, and sisters for believing in me, and for supporting me in all I do. I would like to thank my brothers’ families for always encouraging me to reach higher. Thank you to my best friend, Bryan, for always being there, and for reminding me of my greatest goals and desires.

To my chair, Carol Wilkinson, my deepest admiration and gratitude goes out to you for your love for teaching, for your patience, and for your direction and guidance in all aspects of life. Thank you to my committee members, S. Vincent and K. Prusak, for inspiring me, both professionally and personally. 


\section{Table of Contents}

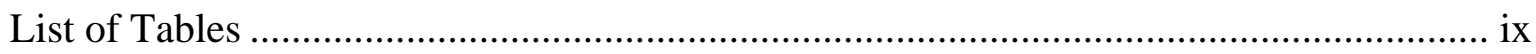

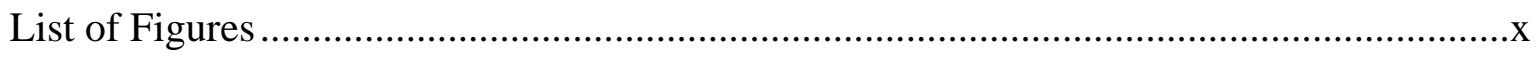

The Effect of Choice on Student Motivation and Physical Activity Behavior in Physical

Education

Abstract

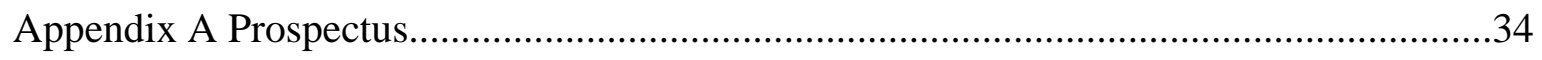

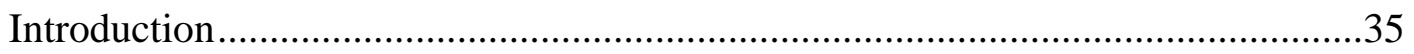

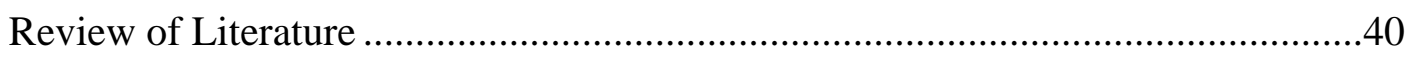

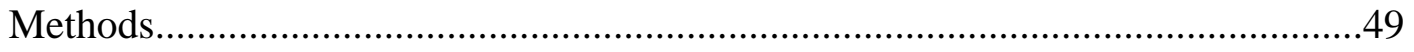

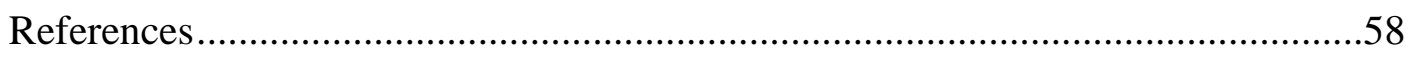

Appendix A-1 Student Handout and Schedule ..................................................65

Appendix A-2 Informed Consent and Surveys .............................................67 
List of Tables

Table Page

1 Schedule of Activities for the No-Choice Group .............................................26

2 Schedule of Activities for the Choice Group .....................................................27

3 Internal Consistency Values: Cronbach’s Alpha and Pearson Correlation for SMS .28

4 Internal Consistency Values: Cronbach’s Alpha and Pearson Correlation for SIMS

5 Means, Standard Deviations, and Effect Sizes Between Groups on SIMS

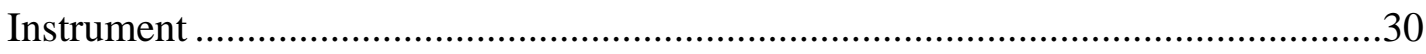

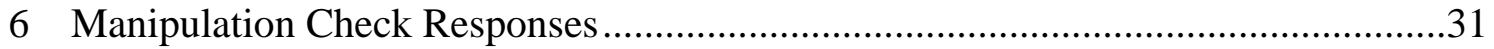

7 Means and Standard Deviations of Pedometer Step Counts...................................32 


\section{List of Figures}

\section{Figures}

Page

1 The Effect of Choice on Student Motivation ....................................................33 
Running Head: EFFECTS OF CHOICE

THE EFFECTS OF CHOICE ON STUDENT MOTIVATION AND PHYSICAL ACTIVITY BEHAVIOR IN PHYSICAL EDUCATION

Jillian Ward, M.S.

Brigham Young University

Carol Wilkinson, Ed.D.

Brigham Young University

Susan D. Vincent, Ph.D.

Brigham Young University

Keven A. Prusak, Ph.D.

Brigham Young University

Send Correspondence to:

Jillian Ward

13316 Valleyheart Dr. North

Sherman Oaks, CA 91423

jillwa@provo.edu

(801) 362-9015 


\title{
2 EFFECTS OF CHOICE
}

\begin{abstract}
Public school physical educators have the opportunity to help students understand the importance of engaging in regular physical activity in order to combat America’s obesity problem. However, students are often unmotivated to participate in their physical education classes. Providing students with an autonomy supportive environment increases intrinsic motivation. Self-determination theory states that higher levels of intrinsic motivation should lead to an increase in behavior, or higher activity levels in a physical education class.

This study examined (a) the effects of increased autonomy on self-determination, and (b) the effects of increased autonomy on physical activity levels. Seventh and eighth grade girls ( $\mathrm{n}=$ 122) in four classes participated in two fitness units (one allowing choice of activities, the other no choice). The 14-item abridged Situational Motivation Scale (SIMS) was administered pre and post each unit. Pedometers were used to measure step counts during both units. Results of the SIMS data showed there was a significant difference in motivation between the trials for all students, and between the groups (pre and post) during the second unit. There was no significant difference in step counts for all students between Unit 1 and Unit 2, and no difference between groups. The results revealed that increased autonomy in activity selection increases student selfdetermination, and therefore, should be implemented into the physical education curriculum. To truly determine the relationship between increased autonomy and activity levels, students need to be in an environment where they can be responsible for their own behavior, and where they can choose how much effort they are willing to put into the activities they have chosen.
\end{abstract}

Keywords: autonomy, self-determination theory, physical activity levels, fitness 


\section{Introduction}

Obesity is considered to be one of America's leading public health problems in today’s society (Welk \& Blair, 2000). Approximately 11\% of U.S. children and youth are overweight (United States Department of Health and Human Services, 2000). Diseases such as hypertension, coronary heart disease, Type 2 diabetes, gall bladder disease, dyslipidemia, respiratory diseases, osteoarthritis, and various cancers are all linked to high levels of obesity (Pi-Sunyer, 1999). One of the main reasons for the increasing number of obese children may be due to the lack of physical activity among Americans of all ages.

According to the Surgeon General's Report on Physical Activity and Health (USDHHS, 1996), 14\% of young people the ages of 12 to 21 report no physical activity at all. In 1999, only 27\% of students in grades 9 to 12 engaged in moderate physical activity five or more days per week for longer than 30 minutes (USDHHS, 2000). In addition to youth inactivity, the number of adults reporting no physical activity at all has increased from 25\% in 1994 (USDHHS, 1996) to 40\% in 1997 (USDHHS, 2000) - a statistic that has almost doubled in only three years. Shephard (1995) suggests that regular physical activity is a deterrent to many of the aforementioned medical conditions, yet too many adolescents and adults are still not participating regularly in a physically active lifestyle.

These unhealthy trends in society could feasibly be due to American adolescents and adults not being properly educated about the benefits of physical activity. It is through physical education that instructors have a prime opportunity to encourage 


\section{EFFECTS OF CHOICE}

children and young adults to participate regularly in physical activity (Sallis \& McKenzie, 1991; Wright, Patterson, \& Cardinal, 2000). However, due to repetitiveness in instructional units and student boredom, there seems to be a lack of motivation for student participation (Bycura \& Darst, 2001; Howard \& Howard, 1997).

Therefore, it seems appropriate for physical educators to develop new ways to more fully motivate their students to participate in class in order to help students develop physically active lifestyles inside and outside of class. Some educators have found that by applying the material to the students’ personal lives (Bycura \& Darst, 2001), teaching with a variety of activities (Griffin \& Maina, 2002), and allowing students to set and achieve personal goals (Bowyer, 1996), their students are more motivated to participate in the activity, and enjoy the activity more.

In addition to appealing to student interests and goal setting, recent research in education has found that giving students control of the learning activities in which they participate in enhances motivation. Deci and Ryan’s (1985) self-determination theory provides a theoretical framework to examine the issues related to motivating students to participate. According to this theory, there are three antecedents that lead to an increase in motivation. Students who are (a) competent, or believe they can succeed in the activity; (b) autonomous, or sense that they have choices; and (c) related, or feel socially successful, will be more motivated to engage in a specific behavior or activity.

The second antecedent, autonomy, is the focus for this particular study. Adolescents have strong desires to be independent from adults, to be autonomous, or to have control (Bycura \& Darst, 2001). Many studies (Deci \& Ryan, 1987; Grolnick \& 
Ryan, 1987; Miserandino, 1996; Prusak, Treasure, Darst \& Pangrazi, 2004) provide evidence that an autonomy supportive environment appeals to student desires to become independent resulting in increased intrinsic motivation.

This increase in motivation occurs as higher levels of self-determination are experienced. Deci and Ryan (1985) propose that there are three motivational states which lie on a continuum of self-determined behavior: (a) amotivation or the lack of motivation; (b) extrinsic motivation or participating for reasons outside of self (i.e., rewards or fear of punishment); and (c) intrinsic motivation or engaging in behavior for reasons within self (i.e., purely for enjoyment in a particular behavior). Whitehead (1999) states that as one moves along the continuum from amotivation to intrinsic motivation, the individual crosses a threshold of autonomy [see Hierarchical model of self-determination theory in Prusak et al., 2004].

Additionally, Deci and Ryan (1985) posit that extrinsic motivation actually occurs at three different levels: external regulation (behaving to attain a reward), introjected regulation (participating because one feels one should), and identified regulation (behavior occurs to achieve a desired outcome). There are also three types of intrinsic motivation: intrinsic motivation to know, intrinsic motivation to accomplish, and intrinsic motivation to experience stimulation (see Vallerand, 1997 for further explanation).

In a physical education setting, Prusak et al. (2004) discovered significant differences in self-determination between groups that were given choice and groups that were not. Groups that were given choice were less amotivated, less externally regulated, and more intrinsically motivated. The study showed that when student autonomy is 


\section{EFFECTS OF CHOICE}

present in selecting learning activities, students are more likely to be motivated to participate.

Further, in the self-determination theory (Deci \& Ryan, 1985), it is proposed that as students move along the motivation continuum from amotivation towards intrinsic motivation, there will be an increase in cognition (deeper understanding), behavior (increased participation), and affect (better attitude). Thus, the intrinsically motivated student will more likely practice physically active behaviors in class, and possibly become physically active on his/her own.

The prevalence of obesity is rising in America, and physical educators can help to instigate changes in student activity levels. By adding choice into the curriculum, intrinsic motivation increases (Deci \& Ryan, 1987; Grolnick \& Ryan, 1987; Miserandino, 1996; Prusak et al., 2004), and in-class physical activity levels should rise as well. Hopefully, this increase in motivation and activity levels will remain throughout the lives of the students.

Purpose

The purpose of this study is to examine (a) the effects of increased autonomy on self-determination, and (b) the effects of increased autonomy on physical activity levels.

\section{Methods}

\section{Participants}

Participants in this study were seventh- and eighth-grade adolescent girls $(\mathrm{n}=$ 122) enrolled in one of four seventh- and eighth-grade combined female classes from a 
local middle school with an average enrollment of 32.8 students per class (range $=29$ to 38).

Instruments

Pedometer. A Walk4Life MLS 2015 (Walk4Life, Plainfield, Illinois) pedometer was used to measure step counts (an indicator of physical activity levels) of every student in each class. The dependent variable was the mean number of steps over a seven-day fitness unit. The independent variable was the level of autonomy (choice or no choice). Step counts were recorded daily at the end of each class period. Individual student pedometer step counts were averaged at the conclusion of each seven-day fitness unit and class means were computed for a comparison between the two treatment models (seven days of choice, and seven days of no choice).

Walk4Life pedometers have been tested for objectivity, reliability, and validity. Specifically, the Walk4Life LS 2525 model was tested for accuracy, and proved to be accurate within $\pm 1 \%$ of actual steps taken (Crouter, Schneider, Karabulut, \& Basset, Jr., 2003). A later study measured the accuracy of the same model, and found the Walk4Life LS 2525 pedometer to be moderately accurate within $\pm 20 \%$ of the correct number of steps 95\% of the time (Schneider, Crouter, Lukajic, \& Basset, Jr., 2003). Although pedometers are only sensitive to locomotor forms of movement, and they are not able to record the magnitude of movement, many tests have shown that pedometers are valid assessments of total volume of physical activity performed by children (Trost, 2001).

Situational Motivation Scale (SIMS). The 14-item SIMS (see full scale in Guay, Vallerand, \& Blanchard, 2000; see abridged scale in Standage, Treasure, Duda, \& Prusak, 


\section{EFFECTS OF CHOICE}

2003) was used to evaluate students' situational motivation across groups. The SIMS has shown to be a valid and reliable tool for measuring self-determination index on many accounts (factorial validity, internal consistency, and multigroup invariance), and in many physical activity contexts (Standage, et al., 2003). The SIMS was administered four times, pre and post the first seven-day unit, and pre and post the second seven-day unit. Participants responded to the stem question, "Why have you been participating in these specific activities (rope jumping, aerobics, kickboxing, etc.) over the past seven days?” Items were rated on a 7-point Likert scale ranging from 1 “corresponds not at all” to 7 “corresponds exactly.”

The independent variable was the level of autonomy (choice or no choice). The dependent variables were represented in four subscale scores derived from the 14-item SIMS (Guay, et al., 2000; Standage et al., 2003). The four subscales assess (a) IM intrinsic motivation (4 items), (b) IDR - identified regulation (3 items), (c) ER - external regulation (3 items), and (d) AM - amotivation (4 items).

Data was reduced by (a) calculating each subscale score via the mean of its items and (b) further reduction by calculating the self-determination index (SDI) score via the following formula: (SDI $=+2(\mathrm{IM})+1(\mathrm{IDR})-1(\mathrm{ER})-2(\mathrm{AM}))$. The SDI, representing the strength of one's self-determination, is a straightforward weighting - the higher the number the stronger the self-determination.

Sport Motivation Scale (SMS). The SMS is an English translation of the French motivation scale l'Echelle de Motivation vis-à-vis les Sports (EMS) (Brière, Vallerand, Blais, \& Pelletier, 1995). Research (Pelletier, Fortier, Vallerand, Tuson, Brière, \& Blais, 
1995) indicates that the SMS measures contextual motivation with adequate levels of construct validity, and internal consistency.

A 16-item, 4-factor abridged version (amotivation, external regulation, identified regulation, and intrinsic motivation to know) of the full SMS (see full scale in Pelletier et al., 1995; see abridged scale in Guay, Mageau, \& Vallerand, 2003) was administered to students in physical education classes. This model is recommended for use in the physical education setting for its brevity, which may invoke more thoughtful responses from the students (Prusak, Christensen, Standage, \& Treasure, in review).

Participants responded to the stem question, "Why do you participate in physical education?” Items were rated on a 7-point Likert scale ranging from 1 “does not describe me at all” to 7 “ describes me exactly.” Data reduction followed the same procedure as for the SIMS.

Procedures

One month prior to the fitness unit, students were administered the SMS to measure contextual motivation and account for any motivational differences between classes before treatment was given. The four classes were randomly assigned to two groups to determine the fitness unit they would participate in first (choice or no choice). Two weeks later, the first phase of manipulation began. The instructor prepared students for the fitness activities by introducing the concept of choice or no choice. When speaking to the choice groups, the instructor made statements such as:

In two weeks we will begin a cardiovascular fitness unit where you are going to 


\section{EFFECTS OF CHOICE}

make a lot of choices. You can choose what activity you participate in, you can choose how hard you are going to work, what goals you are aiming for, and even who you are going to participate with. You will never have to participate in an activity that you do not like because you get to make the choice.

However, when speaking to the no-choice groups, the instructor made comments such as: In two weeks we are going to begin a cardiovascular fitness unit that I am really excited about. It is going to be a lot of fun, and I am going to make a lot of decisions for you. I will assign you to a team that you get to work with everyday, so you will get to know each other really well. Then, I will assign each team to a different activity everyday. You will have the opportunity to participate in every activity that this unit offers, which is really exciting!

Continuing with phase one of manipulation, every student was asked to keep feelings about the treatment confidential until the end of the unit when they would be able to share those feelings on the SIMS. This was done in the attempt to avoid contamination between the two groups.

Two classes participated in the choice cardiovascular fitness unit for the first seven days. Participation in a three-week volleyball unit followed to relieve student burnout. Following the three-week interval, students participated in the no-choice fitness unit for seven days. The other two classes had the no-choice treatment first, the threeweek instructional unit, followed by the choice treatment. The same physical education instructor taught all four classes for the duration of the study. 
During the instructional unit preceding the study, students were oriented to the pedometers, given instructions for proper use, and were allowed practice time with the pedometers before data collection began. This process is valuable to the study procedurally as well as accounting for the possibility of reactivity, although previous research (Vincent \& Pangrazi, 2002) focused on this issue, and had shown that no reactivity occurred when elementary students were fully aware that they were being monitored.

Each class was 45 minutes long (35 minutes of instructional time or activity time, and 10 minutes of dressing time). Immediately after the students changed into their uniforms, they got a pedometer out of a box just outside the locker room, and sat down for roll call in the gym. Warm-ups and stretches began five minutes after the tardy bell and lasted five minutes. The students reset their pedometers simultaneously after warmups, directly before actual activity time began. Ten minutes before class was over, students recorded their own step counts on a chart provided for them, cleared pedometer readings for the following period, returned their pedometers to the box, and sat down in roll call for a five-minute fitness or nutrition lesson while stretching. Five minutes remained to allow students to dress for their next class period.

Activities included four high intensity cardiovascular activities: (a) jogging, (b) kickboxing, (c) aerobics, and (d) rope jumping. Three of the four activities (different combination each day) were available on days 1, 3, 5, and 7 (see Tables 1 and 2). On days 2, 4, and 6 the students participated in one of three moderately intense walking games (Prusak \& Darst, 2002) around the perimeter of the gym: (a) Social Brisk Walking 


\section{EFFECTS OF CHOICE}

- students can bring their own music or talk to friends, but they must continue walking at a brisk pace with good form, (b) “Add 'em Up” - playing cards are placed face down in a hula hoop, and students quickly pick one up each time they pass. The student with the most points after 20 minutes wins, and (c) "Every Which Way But Loose” - students walk the length of the gym, and perform locomotor skills such as skipping, hopping, and sliding across the width of the gym while focusing on good form. Before the fitness unit began, the instructor introduced these activities to the students. A handout and schedule was given to each student explaining the activities. This helped to familiarize the students with the unit, making it run more efficiently.

Phase two of manipulation began on the first day of the fitness unit. The instructor continued with the aforementioned manipulation statements, appropriate to the group the class was in, attempting to make the environment clear to every student. The instructor gave the students choices, or made the decisions for them. The instructor continued to encourage students to keep feelings confidential, reminding them to share ideas on the survey at the end of the seven-day unit.

Prior to the first day of data collection, the instructor divided each no-choice class into three teams. The students were required to remain in these teams for the duration of the seven-day unit. Everyday the instructor assigned each team to one of three activities offered that day (no choice schedule in Table 1), where they remained for the entire 20 minutes of activity. Over the course of the seven days, each team participated in all four high intensity, and all three moderate intensity activities. 
Much like the no-choice group, the classes with choice had the same three activities offered on the same days (choice schedule in Table 2). However, the choice group was not divided into teams. Following warm-ups, the students had the opportunity to choose what activity they would participate in, and which students they would participate with. This allowed each student in the choice group to participate in one of the activities three times across the entire seven-day unit if they found they really enjoyed that particular activity. However, if they did not like the activity they chose, they still had to participate in that activity for the duration of the class period, but could choose a different activity for the next class period.

Phase three of manipulation began when the seven-day fitness unit was finished. Immediately following each seven-day unit, the SIMS was administered to students in every class to evaluate their self-determination index. The instructor gave procedures for the SIMS, and administered the survey. The teacher told the students that it was now time for them to share their personal feelings about the unit by answering the questions on the survey.

To determine whether or not students felt they had a choice in each fitness unit, a manipulation check was given to the students, where they responded to the question, "I feel as though I have been participating in a unit that offers choices” after each unit. Answers were rated on the same 7-point Likert scale as the SIMS. Design and Statistical Analysis

Cronbach’s $\alpha$ was used to assess internal consistency and reliability for each subscale for both the SMS and the SIMS. Pearson correlations were also computed 


\section{EFFECTS OF CHOICE}

among the subscales to assess the simplex pattern of both questionnaires. Groups were coded 1 = no choice first and 2 = choice first. Between-group and within-group differences in SDI for the SIMS were analyzed through a repeated measures ANOVA test. Independent $t$ tests were used for further analysis of SDI. Between-group and withingroup differences in SDI for the SMS were analyzed through a one-way ANOVA test. A repeated measures ANOVA test was used to determine significant differences in step counts between groups and across trials. To analyze the manipulation check, a paired samples $t$ test was used. Alpha level was set at $p<0.05$.

The 16-item abridged version of the SMS questionnaire was reduced to 4 subscales (IM to know, IDR, ER, AM) by finding the average of each of the four respective items. Similarly, the 14-item SIMS was reduced to 4 subscales (IM, IDR, ER, AM) through averaging the 3 or 4 respective items to each subscale. (SDI) was calculated by weighting the subscales $(\mathrm{SDI}=+2(\mathrm{IM})+1(\mathrm{IDR})-1(\mathrm{ER})-2(\mathrm{AM}))$. The higher the self-determination index score, the more self-determined the class was. Class means for step counts over each seven-day unit were calculated.

Results

\section{Reliability and Internal Consistency}

Cronbach's $\alpha$ was used to assess internal consistency for the four subscales of the SMS and the SIMS. Cronbach's $\alpha$ values for the SMS are located on the diagonal in Table 3. The overall reliability score for the SMS instrument was 0.70 . Reliability scores are considered adequate when values are $\geq 0.70$. Additionally, the overall reliability score 
for the SIMS instrument was 0.86. SIMS alpha values are located on the diagonal in Table 4.

Simplex Pattern of the SMS

Pearson correlations (shown on Table 3 above the diagonal) were computed between the four SMS subscales, and generally support the simplex pattern of the SMS. Simplex Pattern of the SIMS

Pearson correlations were computed between the four subscales (IM, IDR, ER, and AM) of the fourth trial of the SIMS. All correlations were significant, $p<0.01$. The simplex pattern of the SIMS is generally supported with the exception of the correlation between the IM and AM subscales. Although there is a significant negative correlation between IM and AM, it is slightly weaker than the adjacent correlation between IM and ER (see Table 4, above diagonal).

Contextual Motivation

Results from the one-way ANOVA test revealed no significant difference on SMS responses among all students before any treatment was given $(F(1,120)=1.66, p=$ 0.200), indicating that no pre-existing differences in contextual motivation were present between the two groups.

Situational Motivation

Descriptive statistics for SDI (means, standard deviations, and effect sizes) on SIMS 1, 2, 3, and 4 are shown in Table 5. Results from the repeated measures ANOVA test indicated a significant difference in SDI between the trials $(F(3,333)=4.87, p<$ 0.007). Tukey’s post hoc tests revealed significant differences between all trials, except 


\section{EFFECTS OF CHOICE}

for Trials 1 and 2 for the choice group. Repeated measures ANOVA also showed a significant difference in motivation between the groups $(F(1,111)=7.5, p<0.007)$. Tukey’s post hoc tests revealed that the significant differences between groups were found at SDI3 $(F(1,118)=8.2, p<0.005)$, and at SDI4 $(F(1,113)=28.2, p<0.000)$. Student responses on the SIMS can be seen in Figure 1. Additionally, a significant interaction for trials and groups was revealed $(F(3,333)=46.1, p<0.000)$. Cohen's D effect sizes were calculated to determine the strength of the effect of the treatment, and indicated that no effect occurred at SDI1 (-0.11) and SDI2 (-0.0017), but revealed a moderate effect (0.65) at SDI3, and a large effect (1.15) at SDI4 (See Table 5). This shows that the longer the treatment persisted, the greater the effect. Manipulation Check

Results from the paired samples $t$ test displayed a significant difference in responses from Group 1 between Unit 1 and Unit 2, $\left(t_{(1,56)}=-6.16, p<0.00\right)$. A significant difference in responses from Group 2 between Unit 1 and Unit 2 were present as well, $\left(t_{(1,55)}=7.83, p<0.00\right)$. Looking at the means in Table 6, it is clear that students understood the type of manipulation they received for each unit.

\section{Physical Activity Behavior through Pedometers}

Descriptive statistics (means and standard deviations) for pedometer step counts can be seen in Table 7. Results from the repeated measures ANOVA test showed no significant differences in pedometer step counts for all students between Unit 1 and Unit $2,(F(1,109)=0.33, p=0.567)$. In addition, no significant differences were found in pedometer step counts between groups $(F(1,109)=2.99, p=0.086)$. 


\section{Discussion}

Physical education instructors have an incredible opportunity to encourage students to participate regularly in physical activity (Sallis \& McKenzie, 1991; Wright et al., 2000). Unhealthy trends in physical activity (USDHHS, 1996; USDHHS, 2000), suggest that current physical education practices do not motivate students enough to participate in class.

This study examined the effect of choice on student motivation and on student physical activity levels. This study was conducted within the framework of Deci \& Ryan’s (1985) self-determination theory, which asserts that increased levels of autonomy will lead to higher levels of intrinsic motivation, thus leading to an increase in behavior (greater physical activity levels in a physical education setting). The general findings of this study reveal that an autonomy supportive environment does lead to greater selfdetermination, but does not necessarily cause an increase in activity levels within the confines of a physical education setting.

Past research (Standage et al., 2003) states that the SIMS is a valid and reliable instrument for measuring motivation. The results of this study provide further evidence of the validity and reliability of the SIMS. Although correlations between the subscales IM/ER and IM/AM may be imperfect (see Table 4), they still continue to generally support the theoretical constructs of the simplex pattern. It is possible that in this particular study, the students did not fully distinguish between the ER and AM items on the survey because the students did not have the option to be completely amotivated (i.e., 


\section{EFFECTS OF CHOICE}

voluntary withdrawal) because their instructor still encouraged them to participate, and they did not have the option to sit out.

Results from the SIMS can be seen in Figure 1. There are two possible reasons why significant differences did not occur between the groups at Unit 1 , yet were present at Unit 2. The first explanation for the groups having a similar self-determination index score at the first and second trials of the SIMS could be due to the obedient nature of students. On average, most students will do what their teachers ask them to do. Therefore, it is possible that the no-choice group was just as self-determined as the choice group simply because they assumed that in physical education, they were supposed to do whatever the teacher asked them to do. Similarly, the choice group may have assumed that their instructor had always given students choice for that particular fitness unit. It was not until the students received the opposite treatment that significant changes in selfdetermination occurred. Hence, it was the contrast with what they were doing in unit one that truly caused the increase or decrease in SDI.

A second, less probable reason for these results could be because the students did not fully understand the survey. The first two times the students took the SIMS, it may not have been clear to them that their responses should have focused on the individual activities, not the fitness unit as a whole. Responding to the survey this way may have caused the choice group to express that they did not have a choice because they still had to participate in the fitness unit, thus causing the students, regardless of group, to be at equal levels of self-determination. 
Research (Grolnick \& Ryan, 1987; Miserandino, 1996, Prusak et al., 2004) indicates that autonomy supportive environments will increase intrinsic motivation. The results of the third and fourth SIMS trials strongly support this statement. When the nochoice group received the choice treatment, students became significantly more selfdetermined. Not only were they more self-determined from Trial 2 to Trial 3, but their self-determination continued to increase from Trials 3 to Trial 4, increasing the betweengroup difference by an even greater margin (see Figure 1).

If student autonomy increases self-determination, maybe the opposite will also be true. By taking away student autonomy, self-determination should decrease as well. This idea was supported with disgruntled comments from the students who were in the choice group first. As soon as they realized they were no longer going to get choice in the second unit, the instructor heard the students comment about how upset they were that their choice was going to be taken away. Miserandino (1996) found that when students felt their autonomy was compromised, intrinsic motivation diminished. Likewise, in this study, once the choice group had their autonomy revoked, their SDI score plummeted, and continued to do so at the fourth trial.

In addition to analyzing student motivation, another purpose for this study was to analyze the effect of choice on activity levels (see Table 7). Deci \& Ryan’s (1985) selfdetermination theory further states that increased motivation will lead to increased behavior (or increased activity levels in a physical education class). Thompson \& Wankel (1980) found that women who perceived choice in their activities would tolerate an 


\section{EFFECTS OF CHOICE}

activity for a longer period of time because they selected it. This should directly relate to higher activity levels.

While the results of these studies are logical, applying the theory to the physical education setting is much more difficult. It was hypothesized that activity levels would increase, however, no significant differences in step counts were found between groups. A possible explanation for this may be due to the nature of physical education classes. A primary goal in physical education is for students to be active. Therefore, in physical education, students are not given the option to not participate. Physical educators expect their students to be active for the entire class period, and constantly encourage them to do so. In other words, regardless of how motivated each individual student is, if they are all participating in the same activities, and under the observation of their teacher, their step counts will be very similar.

\section{Conclusion}

The limitations of this study call for future research in this area. First, this study limits itself to only one type of unit - fitness. Second, a study must be designed where students are responsible for their own level of behavior, where they are still assigned or have the opportunity to choose an activity, however, within that activity, they may choose how much effort they are willing to put forth, or they can choose not to participate without facing any repercussions.

Meanwhile, this study has provided evidence of the need for student choice in the physical education setting. In order to increase student self-determination, physical educators can provide students with an autonomy supportive environment, and perhaps 
positively affect activity levels in class. However, even if choice does not affect in-class activity levels, implementing it into the physical education curriculum would still be beneficial because it does increase student self-determination. Although a primary goal in physical education is for all students to be active, a more important goal is to help the youth of today become motivated enough to begin their own pattern of lifetime physical activity, a goal that can be achieved through increased autonomy in physical education. 


\section{EFFECTS OF CHOICE}

\section{References}

Bowyer, G. R. (1996). Student perceptions of physical education. Journal of Physical Education, Recreation \& Dance, 67(1), 23-26.

Brière, N. M., Vallerand, R. J., Blais, M. R., \& Pelletier, L. G. (1995). Dèvelopement et validation d'une measure de motivation intrinsèque et extrinsèque et d'amotivation en contexte sportif: L'Echelle de Motivation vis-à-vis les Sports (EMS). [Development and validation of the French form of the Sport Motivation Scale]. International Journal of Sport Psychology, 26, 465-489.

Bycura, D., \& Darst, P. W. (2001). Motivating middle school students: A health-club approach. Journal of Physical Education, Recreation \& Dance, 72(7), 24-29.

Crouter, S. E., Schneider, P. L., Karabulut, M., \& Basset, D. R. Jr., (2003). Validity of 10 electronic pedometers for measuring steps distance, and energy cost. Medicine and Science in Sports and Exercise, 35(8), 1455-1460.

Deci, E. L., \& Ryan, R. M. (1985). Intrinsic motivation and self-determination in human behavior (2nd ed.). New York: Plenum Press.

Deci, E. L., \& Ryan, R. M. (1987). The support of autonomy and the control of behavior. Journal of Personality and Social Psychology, 53(6), 1024-1037.

Griffin, M. R., \& Maina, M. P. (2002). Focus on interest diversity in high school physical education. Strategies, 15(6), 11-12.

Grolnick, W. S., \& Ryan, R. M. (1987). Autonomy in children’s learning: An experimental and individual difference investigation. Journal of Personality and Social Psychology, 52, 890-898. 
Guay, F., Mageau, G. A., \& Vallerand, R. J. (2003). On the hierarchical structure of selfdetermined motivation: A test of top-down, bottom-up, reciprocal, and horizontal effects. Personality and Social Psychology Bulletin, 29, 992-1004.

Guay, F., Vallerand, R. J., \& Blanchard, C. (2000). On the assessment of state intrinsic and extrinsic motivation: The situational motivation scale (SIMS). Motivation and Emotion, 24, 175-213.

Howard, B. K., \& Howard, M. R. (1997). What a difference a choice makes! Strategies, 10(3), 16-20.

Miserandino, M. (1996). Children who do well in school: Individual differences in perceived competence and autonomy in above average children. Journal of Educational Psychology, 88, 203-214.

Pelletier, L. G., Fortier, M. S., Vallerand, R. J., Tuson, K. M., Brière, N. M., \& Blais, M. R. (1995). Towards a new measure of intrinsic motivation, extrinsic motivation, and amotivation in sports: The Sport Motivation Scale. Journal of Sport and Exercise Psychology, 17, 35-53.

Pi-Sunyer, F. X. (1999). Comorbidities of overweight and obesity: Current evidence and research issues. Medicine and Science in Sports and Exercise, 31, S602-S608.

Prusak, K. A., Christensen, W., Standage, M., \& Treasure, D. (in review). The Sport Motivation Scale in physical education: A confirmatory factor analysis.

Prusak, K. A., \& Darst, P. W. (2002). Effects of types of walking activities on actual choices by adolescent female physical education students. Journal of Teaching in Physical Education, 21, 230-241. 


\section{EFFECTS OF CHOICE}

Prusak, K. A., Treasure, D. C., Darst, P. W., \& Pangrazi, R. (2004). The effects of choice on the motivation of adolescent girls in physical education. Journal of Teaching in Physical Education, 23, 19-29.

Sallis, J., \& McKenzie, T. L. (1991). Physical education’s role in public health. Research Quarterly for Exercise and Sport, 62, 124-137.

Schneider, P. L., Crouter, S. E., Lukajic, O., \& Basset, D. R. Jr., (2003). Accuracy and reliability of ten pedometers for measuring steps over a 400-m walk. Medicine and Science in Sports and Exercise, 35(10), 1179-1784.

Shephard, R. J. (1995). Physical activity, fitness, and health: The current consensus. Quest, 47, 288-303.

Standage, M., Treasure, D. C., Duda, J. L., \& Prusak, K. A. (2003). Validity, reliability, and invariance of the situational motivation scale (SIMS) across diverse physical activity contexts. Journal of Sport and Exercise Psychology, 25, 19-43.

Thompson, C. E., \& Wankel, L. M. (1980). The effects of perceived activity choice upon frequency of exercise behavior. Journal of Applied Social Psychology, 10(5), 436-443.

Trost, S. G. (2001). Objective measurement of physical activity in youth: Current issues, future directions. Exercise and Sport Sciences Reviews, 29(1), 32-36.

U.S. Department of Health and Human Services. (1996). Physical Activity and Health: A Report of the Surgeon General, U.S. Department of Health and Human Services, Centers for Disease Control and Prevention, National Center for Chronic Disease Prevention and Health Promotion, Atlanta, GA. 
U.S. Department of Health and Human Services. (2000). Healthy People 2010: Understanding and Improving Health. 2nd ed. Washington, D.C: U.S. Government Printing Office.

Vallerand, R. J. (1997). Toward a hierarchical model of intrinsic and extrinsic motivation. In M. P. Zanna (Ed.), Advances in experimental social psychology: Vol 29 (pp. 271-360). New York: Academic Press.

Vincent, S. D., \& Pangrazi, R. P. (2002). Does reactivity exist in children when measuring activity levels with pedometers? Pediatric Exercise Science, 14(1), 5663.

Welk, G. J., \& Blair, S. N. (2000). Physical activity protects against the health risks of obesity. [Electronic version]. President's Council on Physical Fitness and Sports Research Digest, 3(12), 1-10. http://fitness.gov/Reading_Room/ Digests/digests.html.

Whitehead, J. R. (1999). Physical activity and intrinsic motivation. Toward a Better Understanding of Physical Fitness and Activity, 1(2), 33-40.

Wright, M. T., Patterson, D. L., \& Cardinal, B. J. (2000). Increasing children’s physical activity. Journal of Physical Education, Recreation \& Dance, 71(1), 26-29. 


\section{EFFECTS OF CHOICE}

Table 1

Schedule of Activities for the No-Choice Group

\begin{tabular}{llll}
\hline Day & Team 1 & Team 2 & Team 3 \\
\hline 1 & Jogging & Kickboxing & Aerobics \\
2 & Walking Game 1 & Walking Game 2 & Walking Game 3 \\
3 & Kickboxing & Aerobics & Rope Jumping \\
4 & Walking Game 2 & Walking Game 3 & Walking Game 1 \\
5 & Aerobics & Rope Jumping & Jogging \\
7 & Walking Game 3 & Walking Game 1 & Walking Game 2 \\
\hline
\end{tabular}

Note. Walking game options are: (1) Social Brisk Walking, (2) “Add ‘em Up”, and (3)

“Every Which Way But Loose” (Prusak \& Darst, 2002). Aerobics and Kickboxing activities are taught through video instruction. 
Table 2

Schedule of Activities for the Choice Group

\begin{tabular}{llll}
\hline Day & Option 1 & Option 2 & Option 3 \\
\hline 1 & Jogging & Kickboxing & Aerobics \\
2 & Walking Game 1 & Walking Game 2 & Walking Game 3 \\
3 & Kickboxing & Aerobics & Rope Jumping \\
4 & Walking Game 2 & Walking Game 3 & Walking Game 1 \\
5 & Aerobics & Rope Jumping & Jogging \\
7 & Walking Game 3 & Walking Game 1 & Walking Game 2 \\
\hline
\end{tabular}

Note. Walking game options are: (1) Social Brisk Walking, (2) “Add 'em Up”, and (3)

“Every Which Way But Loose” (Prusak \& Darst, 2002). Aerobics and Kickboxing activities are taught through video instruction. 


\section{EFFECTS OF CHOICE}

Table 3

Internal Consistency Values: Cronbach's Alpha and Pearson Correlation for SMS

\begin{tabular}{|c|c|c|c|c|c|}
\hline SMS Subscales & 1 & 2 & 3 & 4 & $M \alpha$ \\
\hline Intrinsic Motivation to Know & $(.73)$ & $.48 * *$ & $.28 * *$ & $-.27 * *$ & \\
\hline Identified Regulation & & $(.67)$ & $.42 * *$ & -.09 & \\
\hline External Regulation & & & $(.64)$ & .10 & \\
\hline Amotivation & & & & $(.76)$ & \\
\hline
\end{tabular}

**Significant correlations $p<.01$; ${ }^{\circ}$ Mean alpha of all SMS subscales 
EFFECTS OF CHOICE 29

Table 4

Internal Consistency Values: Cronbach's Alpha and Pearson Correlation for SIMS

\begin{tabular}{lccccc}
\hline SIMS Subscales & 1 & 2 & 3 & 4 & $M \alpha$ \\
\hline Intrinsic Motivation & $(.89) \dagger$ & $.76^{* *}$ & $-.59^{* *}$ & $-.54^{* *}$ & \\
Identified Regulation & & $(.85) \dagger$ & $-.35^{* *}$ & $-.51^{* *}$ \\
External Regulation & & & $(.88) \dagger$ & $.46^{* *}$ & \\
Amotivation & & & & $(.81) \dagger$ & \\
& & & & & $(.86)^{\circ}$ \\
\hline
\end{tabular}

Note. Correlations above the diagonal are representative of the fourth SIMS trial.

**Significant correlations $p<.01$; †Mean alphas of all four SIMS surveys; ${ }^{\circ}$ Mean alpha

of all SIMS subscales 
30 EFFECTS OF CHOICE

Table 5

Means, Standard Deviations, and Effect Sizes between Groups on SIMS Instrument

\begin{tabular}{|c|c|c|c|}
\hline SIMS Trial & M & $\mathrm{SD}$ & ES \\
\hline \multicolumn{4}{|l|}{ SIMS 1 (SDI) } \\
\hline Group 1 (No choice) & 7.53 & 5.74 & -0.11 \\
\hline 2 (Choice) & 8.17 & 5.65 & \\
\hline \multicolumn{4}{|l|}{ SIMS 2 (SDI) } \\
\hline Group 1 (No choice) & 8.62 & 6.08 & -.002 \\
\hline 2 (Choice) & 8.63 & 5.64 & \\
\hline \multicolumn{4}{|l|}{ SIMS 3 (SDI) } \\
\hline Group 1 (Choice) & $9.75 *$ & 6.04 & $.65 † \dagger$ \\
\hline 2 (No choice) & 5.54 & 6.88 & \\
\hline \multicolumn{4}{|l|}{ SIMS 4 (SDI) } \\
\hline Group 1 (Choice) & $11.07 *$ & 5.98 & $1.15 † \dagger \dagger$ \\
\hline 2 (No choice) & 2.96 & 8.03 & \\
\hline
\end{tabular}

Note. Group 1 received no choice for Trials 1 and 2, and choice for Trials 3 and 4; Group 2 received choice for Trials 1 and 2, and no choice for Trials 3 and 4 .

* Significant difference between groups, $p<0.05$; $† \dagger$ Moderate effect size; $\uparrow \dagger \dagger$ Large effect size 
Table 6

Manipulation Check Responses

\begin{tabular}{lll}
\hline Group & $\mathrm{M}$ & $\mathrm{SD}$ \\
\hline Group 1 & & \\
Post Unit 1 (No choice) & 4.84 & 1.92 \\
Post Unit 2 (Choice) & $6.28^{* *}$ & 1.31 \\
& & \\
Group 2 & & \\
Post Unit 1 (Choice) & 5.96 & 1.48 \\
Post Unit 2 (No choice) & $3.71^{* *}$ & 2.19 \\
\end{tabular}

Note. Group 1 received no choice in Unit 1 and choice in Unit 2. Group 2 received choice in Unit 1 and no choice in Unit 2. The manipulation check was given at the end of each unit.

** Significant difference between responses, $p<0.000$ 
32 EFFECTS OF CHOICE

Table 7

Means and Standard Deviations of Pedometer Step Counts

\begin{tabular}{lcc}
\hline Unit & M & SD \\
\hline UNIT 1 & & \\
Group 1 (No choice) & 2258.11 & 279.34 \\
Group 2 (Choice) & 2125.68 & 236.97 \\
UNIT 1 & & \\
Group 1 (Choice) & 2202.71 & 180.38 \\
Group 2 (No choice) & 2204.57 & 217.34 \\
\hline
\end{tabular}

Note. Group 1 received no choice for Unit 1, and choice for Unit 2; Group 2 received choice for Unit 1, and no choice for Unit 2. 
The Effect of Choice on Student Motivation

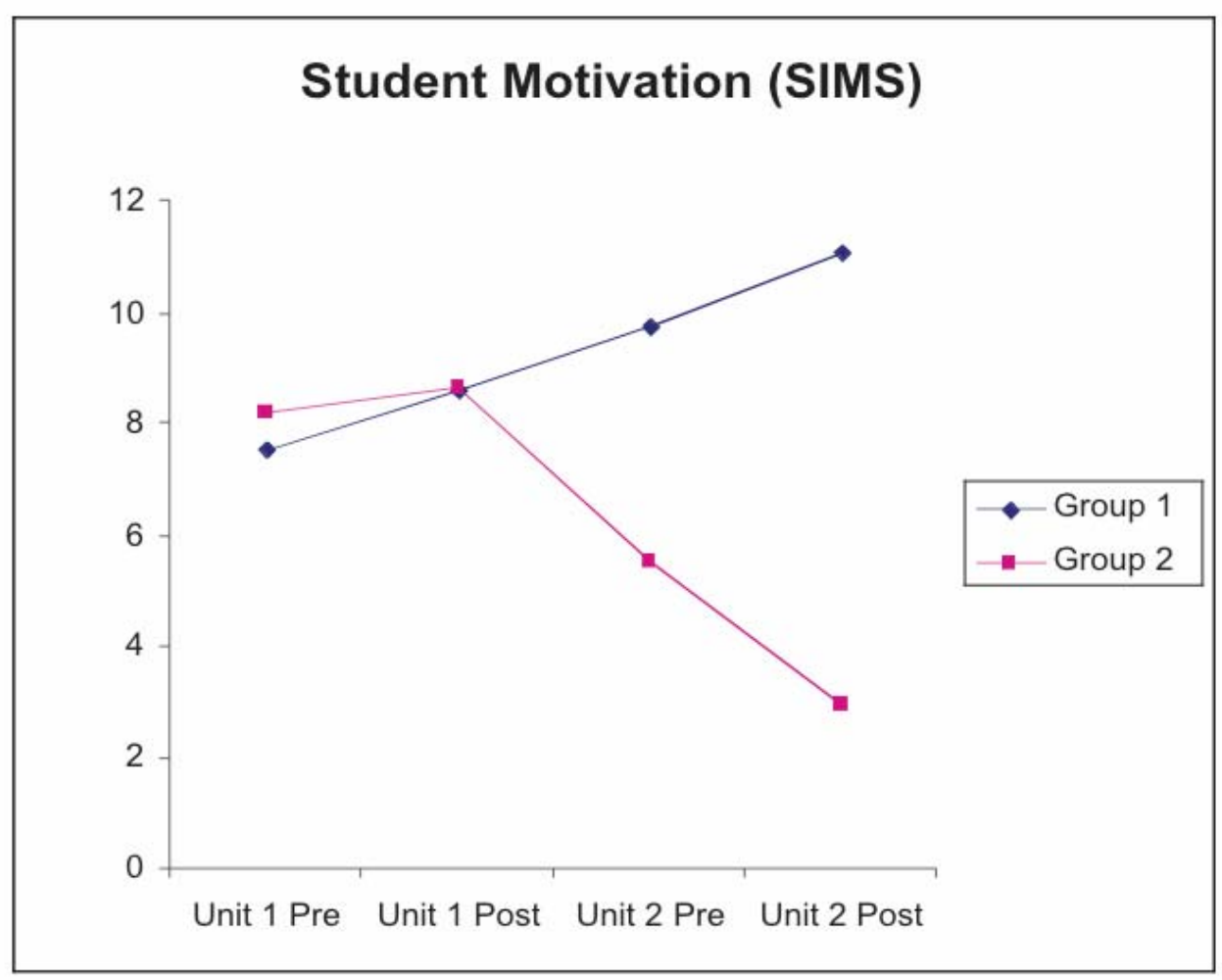

Figure 1. Group 1 received the no-choice treatment for Unit 1, but received choice for Unit 2. Group 2 received the choice treatment for Unit 1 , but received no choice for Unit 2. 
Appendix A

Prospectus 


\section{Chapter 1}

\section{Introduction}

Obesity is considered to be one of America's leading public health problems in today’s society (Welk \& Blair, 2000). Diseases such as hypertension, coronary heart disease, Type 2 diabetes, gall bladder disease, dyslipidemia, respiratory diseases, osteoarthritis, and various cancers are all linked to high levels of obesity (Pi-Sunyer, 1999). Approximately $11 \%$ of U.S. children and youth are significantly overweight (United States Department of Health and Human Services, 2000).

One of the main reasons for the increasing number of obese children may be due to the lack of physical activity among Americans of all ages. According to the Surgeon General's Report on Physical Activity and Health (USDHHS, 1996), 14\% of young people the ages of 12 to 21 report no physical activity at all. In 1999, only $27 \%$ of students in grades 9 to 12 engaged in moderate physical activity five or more days per week for longer than 30 minutes (USDHHS, 2000). In addition to youth inactivity, the number of adults reporting no physical activity at all has increased from 25\% in 1994 (USDHHS, 1996) to 40\% in 1997 (USDHHS, 2000).

These unhealthy trends in society could feasibly be due to American adolescents and adults not being properly educated about the benefits of physical activity. It is through physical education that instructors have a prime opportunity to encourage children and young adults to participate regularly in physical activity (Sallis \& McKenzie, 1991; Wright, Patterson, \& Cardinal, 2000). However, due to repetitiveness in instructional units and student boredom, there seems to be a lack of motivation for 
student participation (Bycura \& Darst, 2001; Howard \& Howard, 1997). Therefore, it seems appropriate for physical educators to develop new ways to more fully motivate their students to participate in class in order to help students develop physically active lifestyles inside and outside of class.

In order to motivate students, teachers have found that they need to apply the material to the students' personal lives (Bycura \& Darst, 2001), teach with a variety of activities (Griffin \& Maina, 2002), and allow students to set and achieve goals (Bowyer, 1996). According to Deci \& Ryan’s (1985) self-determination theory of motivation, intrinsic motivation will increase in an autonomy supportive environment. Research indicates that providing students with an autonomy supportive environment will increase intrinsic motivation (Deci \& Ryan, 1987; Grolnick \& Ryan, 1987; Miserandino, 1996; Prusak, Treasure, Darst, \& Pangrazi, 2004).

Self-determination theory further states that higher levels of intrinsic motivation will lead to an increase in behavior (Deci \& Ryan, 1985), or higher activity levels in a physical education class. Because student autonomy positively affects intrinsic motivation, autonomy may positively affect physical activity levels as well. Thompson \& Wankel (1980) found that women who had perceived choice in their activities would tolerate an activity for a longer period of time because they selected it. This should directly relate to higher levels of physical activity.

The prevalence of obesity is rising in America, and physical educators can help to instigate changes in student activity levels. By adding choice into the curriculum, intrinsic motivation increases (Deci \& Ryan, 1987; Grolnick \& Ryan, 1987; Miserandino, 
1996; Prusak et al., 2004), and in-class physical activity levels should rise as well.

Hopefully, this increase in motivation and activity levels will remain throughout the lives of the students.

Problem Statement

The purpose of this study is to examine (a) the effects of increased autonomy on self-determination, and (b) the effects of increased autonomy on physical activity levels. Hypothesis

Null: There will be no significant difference in student self-determination and physical activity levels in a fitness unit that offers choice versus a fitness unit without choice.

Alternative: There will be a significant difference in student self-determination and activity levels in a fitness unit that offers choice versus a fitness unit without choice. Operational Definitions

Amotivation - the absence of motivation (Deci \& Ryan, 1985)

Autonomy - the condition of having perceived internal locus of control, and internal locus of causality (Deci \& Ryan, 1985)

External Regulation - non-autonomous behaviors that are dictated by external factors such as reward or payment (Deci \& Ryan, 1985)

Identified Regulation - behaviors that occur when individuals begin to value a specific activity because it is important to personal goals (Deci \& Ryan, 1985)

Intrinsic Motivation - behaviors engaged in for the pleasure that comes from participating in the activity (Deci \& Ryan, 1985) 
Pedometer - a device that can be used to assess physical activity (Crouter, Schneider, Karabulut, and Basset, Jr., 2003)

Assumptions

1. The lesson content will be the same, and will be taught the same way for both the choice treatment, and the no-choice treatment.

2. The participants will wear the assigned pedometer for the duration of the class period.

3. The participants' step counts will not significantly increase (reactivity) because the subject is wearing a pedometer (Vincent \& Pangrazi, 2002).

4. The participants will follow all instructions given for wearing the pedometers.

5. Pedometers will be worn every day, the whole period, for fourteen days (seven days of choice, seven days of no choice).

6. Choice groups will not contaminate no-choice groups.

\section{Delimitations}

This study will be delimited to:

1. Seventh-grade and eighth-grade females from one middle school in the Western United States.

2. Participants will only be wearing pedometers during physical education class.

\section{Limitations}

Possible limitations of this study are:

1. The researcher will serve as the instructor of the class. 
2. The instructor/researcher may subconsciously be more biased towards one group versus another.

3. The sample may not be representative of the entire seventh-grade and eighthgrade population.

4. Participants will record their own pedometer data.

5. Participants may have changes in activity levels because they are aware that they are being measured (reactivity).

6. Students may experience burnout toward the end of the unit.

7. There may be contamination, where choice groups discuss feelings with nochoice groups.

8. Subjects may not follow all instructions for wearing the pedometer for the designated time.

9. Most eighth graders in this study have already participated in a pilot unit involving choice when they were in seventh grade.

Significance of the Study

There is currently a lack of motivation in regular physical education settings. This study will allow us to discover if giving students choice in a fitness unit will increase motivation, thus increasing in-class physical activity levels. 
Chapter 2

Review of Literature

Introduction

Over the past few decades there have been increasing concerns for the health of America's population. Obesity is so prevalent in today's society that it is considered to be one of the leading public health problems facing us today (Welk \& Blair, 2000). How did United States citizens get to this point? What could have been done to prevent this from happening? What can be done now to prevent it from getting worse?

This review will discuss (a) the reasons for an unhealthy America; (b) the need to understand motivation in physical education classes, describing the tenets of the selfdetermination theory; (c) different ways to motivate students; (d) the effects of an autonomy supportive environment on motivation; and (e) the possible effects that student autonomy could have on in-class physical activity levels. The purpose of this study is to examine the effects of increased autonomy on self-determination, and the effects of increased autonomy on physical activity levels.

\section{Reasons for an Unhealthy America}

In Healthy People 2010 (USDHHS, 2000), it states that 11\% of U.S. adolescents from the ages of 12-19 years are overweight or obese. Mokdad, Serdula, Dietz, Bowman, Marks, \& Koplan (1999) found that the prevalence of obesity among adults 18 years or older had increased from $12 \%$ to $18.9 \%$ from 1991 to 1998 . The results of this study provide evidence of a trend of unhealthy behaviors among American citizens. Obesity has been linked to many serious diseases such as hypertension, coronary heart disease, 
Type 2 diabetes, dyslipidemia, gall bladder disease, respiratory diseases, osteoarthritis and various cancers (Pi-Sunyer, 1999).

The most common explanation for these current trends in society is the fact that many environmental and behavioral influences have made it more difficult for individuals to maintain healthy weight levels (Welk \& Blair, 2000). Availability of highfat foods at low cost fast food restaurants (Welk \& Blair, 2000), the move from physical labor occupations to sedentary occupations, and changes in short-distance modes of transportation are all major factors of increasing levels of obesity (Tudor-Locke, 2002).

Perhaps one of the key reasons for these trends, however, is due to the lack of physical activity among Americans of all ages. Shephard (1995) suggests that regular physical activity is a deterrent to many medical conditions such as coronary heart disease, hypertension, Type 2 diabetes, osteoporosis, depression, and anxiety. Despite the strong evidence of the health benefits of physical activity, adolescents and adults are still not participating regularly in a physically active lifestyle.

According to the Surgeon General’s Report on Physical Activity and Health (USDHHS, 1996), 14\% of young people the ages of 12 to 21 report no physical activity at all. In 1999, only $27 \%$ of students in grades 9 to 12 engaged in moderate physical activity five or more days per week for longer than 30 minutes, and 65\% of students in grades 9 to 12 participated in vigorous physical activity for 20 minutes three or more days per week (USDHHS, 2000).

In addition to these unhealthy numbers in adolescents, adult participation in physical activities is also low. In Healthy People 2010 (USDHHS, 2000) it states that 
only $23 \%$ of U.S. adults engage in vigorous physical activity for longer than 20 minutes three or more days per week, and only $15 \%$ of adults participate in physical activities five days a week for 30 minutes or more. The number of adults reporting no physical activity at all has increased from 25\% in 1994 (USDHHS, 1996) to 40\% in 1997 (USDHHS, 2000) - a statistic that has almost doubled in only three years.

The Need to Understand Motivation in Physical Education Classes

Perhaps a reason for these unhealthy trends in society is that American adolescents and adults are not properly educated about the benefits of physical activity. In ninth grade, $80 \%$ of students enroll in physical education; however, by the time they are in twelfth grade, enrollment drops to only $45 \%$ and $39 \%$ of boys and girls, respectively (USDHHS, 1996). Currently, only 29\% of youth in grades 9 to 12 are enrolled in daily physical education (USDHHS, 2000). Given the current numbers of physically active adolescents and adults (USDHHS, 2000), it can be assumed that students who are not enrolled in physical education are not learning about these benefits on their own. Even within physical education classes, students may be escaping the proper education needed to learn of these benefits.

Through physical education, instructors can promote physical activity and shape the minds of youth to participate regularly in a physically active lifestyle (Sallis \& McKenzie, 1991; Wright et al., 2000). It is during physical education class that most students are provided with their primary needs for physical activity (Sallis \& McKenzie, 1991). However, due to repetitiveness in instructional units and student boredom, there seems to be a lack of motivation for student participation (Bycura \& Darst, 2001; Howard 
\& Howard, 1997). Therefore, it seems appropriate for physical educators to develop new ways to better motivate their students to participate in class in order to help students develop physically active lifestyles outside of class.

Self-Determination Theory. Deci \& Ryan’s (1985) self-determination theory provides a theoretical framework to examine the issues related to motivating students to participate. According to the self-determination theory (Deci \& Ryan, 1985), there are three antecedents that lead to an increase in motivation. Students who are (a) competent, or believe they can succeed in the activity; (b) autonomous, or sense that they have choices; and (c) related, or feel socially successful, will be more motivated to engage in a specific behavior or activity.

This increase in motivation occurs as higher levels of self-determination are experienced. Deci \& Ryan (1985) propose that there are three motivational states which lie on a continuum of self-determined behavior: (a) amotivation or the lack of motivation; (b) extrinsic motivation or participating for reasons outside of self (i.e., rewards or fear of punishment); and (c) intrinsic motivation or engaging in behavior for reasons within self (i.e., purely for enjoyment in a particular behavior). Whitehead (1999) states that as one moves along the continuum from amotivation to intrinsic motivation, the individual crosses a threshold of autonomy [see Hierarchical model of self-determination theory in Prusak et al., 2004].

Additionally, Deci and Ryan (1985) posit that extrinsic motivation actually occurs at three different levels: external regulation (behaving to attain a reward), introjected regulation (participating because one feels one should), and identified regulation 
(behavior occurs to achieve a desired outcome). There are also three types of intrinsic motivation: intrinsic motivation to know, intrinsic motivation to accomplish, and intrinsic motivation to experience stimulation (see Vallerand, 1997 for further explanation).

Further, in the self-determination theory it is proposed that as an individual moves along the continuum of self-determined behavior toward intrinsic motivation, there will be an increase in cognition (deeper understanding), behavior (increased participation), and affect (better attitude) (Deci \& Ryan, 1985).

Continuing with Deci and Ryan’s (1985) work, Vallerand (2001) asserts that selfdetermined behaviors occur at different levels of generality: global (motivation towards an active lifestyle in all contexts), contextual (motivation towards physical education), and situational (motivation towards current activities). Vallerand (2001) also states that there are top-down and bottom-up effects of motivation at these levels. In other words, global disposition can affect contextual, which can affect situational disposition, and situational can affect contextual, which may affect global disposition. It is more difficult for physical education instructors to change the global disposition of a student, given this disposition remains quite stable. However, physical educators could have an effect on increasing intrinsic motivation at the contextual and situational levels. This study will focus on the response of motivation at the situational level, and behavioral responses due to an autonomy supportive environment.

Ways to Motivate Students in Physical Education

Physical education instructors have tried many different techniques to help motivate students to participate in physical activity both in and outside of class. Bycura 
and Darst (2001) found the key to motivating middle-school students is to appeal to their interests. Students need to know how the material they are learning applies to them personally. If they do not see the relevance of the subject matter, they will not be motivated to learn that material. Griffin and Maina (2002) focused on teaching high school students with a variety of activities. They found that by doing this, students were more motivated to participate and they enjoyed the activity more, thus causing less discipline problems for the teacher.

Another motivation factor in physical education settings is allowing students to set and achieve personal goals. Bowyer (1996) interviewed preservice teachers, asking them to recall their favorite physical education activities in elementary school. Results of the interview showed that as students, they were much more motivated when the activities encouraged them to set individual goals. Those goals gave the students a purpose for participating in the activities, rather than simply participating because it was required of them. A pilot fitness unit encouraged students to set personal fitness goals and then participate in fitness activities that would help them to achieve those goals. This approach increased student motivation to participate because they were aware of their personal responsibilities to achieve those goals (Bycura \& Darst, 2001). The Effects of an Autonomy Supportive Environment on Motivation

In addition to appealing to student interests and goal setting, recent research in education has found that giving students control of the learning activities they participate in enhances motivation. In Deci and Ryan's (1985) self-determination theory, one of the antecedents that affect self-determination is autonomy. Adolescents have strong desires 
to be independent from adults, to be autonomous, or to have control (Bycura \& Darst, 2001). Many studies (Deci \& Ryan, 1987; Grolnick \& Ryan, 1987; Miserandino, 1996;

Prusak et al., 2004) have shown that an autonomy supportive environment appeals to students’ desires to become independent and increases intrinsic motivation.

The results of Grolnick and Ryan's (1987) study conducted in an educational classroom setting showed that students were more interested in learning in a noncontrolling environment than those who were not. They felt less pressure from their instructors, thus leading to greater degrees of intrinsic motivation. Furthermore, Miserandino (1996) found that when students felt their autonomy was compromised, intrinsic motivation declined. Students expressed more anger and anxiety, and displayed less involvement and persistence in the learning activities.

In a physical education setting, Prusak et al. (2004) discovered significant differences in intrinsic motivation between groups that were given choices and groups that were not. Groups that were given choice were less amotivated, less externally regulated, and more intrinsically motivated. The study showed that when student autonomy is present in selecting learning activities, students are more likely to be motivated to participate.

Olafson (2002) found while interviewing adolescent females, many mentioned that they would enjoy physical education more if they were allowed to choose the activities they participated in (Olafson, 2002). Physical educators show evidence of thoughtful curriculum planning by providing students with a variety of activities and 
allowing them to choose which activity suits them best, while concurrently holding students to higher levels of accountability (Pangrazi, 2001; Prusak et al., 2004). Possible Effects of Autonomy on In-Class Activity Levels

Because student autonomy positively affects intrinsic motivation (Deci \& Ryan, 1987; Grolnick \& Ryan, 1987; Miserandino, 1996; Prusak et al, 2004), an autonomy supportive environment may positively affect in-class physical activity levels as well. Thompson and Wankel (1980) found that women who had perceived choice in their activities would tolerate an activity for a longer period of time because they selected it. This should directly relate to higher levels of physical activity.

The self-determination theory states that as students move along the motivation continuum from amotivation towards intrinsic motivation, cognition increases, they experience a deeper understanding of the subject matter, permanent behavior changes will occur resulting in increased participation in and out of school, and there will be an increase in affect, or positive attitudes will be prevalent (Deci \& Ryan, 1985). Thus, the intrinsically motivated student will more likely practice physically active behaviors in class, and possibly become physically active on his/her own.

\section{Summary}

The health of America is declining, and obesity is becoming more prevalent in today’s society (Welk \& Blair, 2000). One of the main reasons for this decrease in health among American citizens is due to a lack of physical activity (Tudor-Locke, 2002; USDHHS, 2000). A decreasing number of high school students are enrolled in physical 
education (USDHHS, 1996; USDHHS, 2000), thus leading to less informed individuals regarding the benefits of living a physically active lifestyle.

Physical education instructors can promote physical activity and encourage youth to participate regularly in physical activity (Sallis \& McKenzie, 1991; Wright et al., 2000). However, due to repetitiveness in physical education instructional units and student boredom, there seems to be a lack of motivation for student participation (Bycura \& Darst, 2001; Howard \& Howard, 1997). Therefore, it seems appropriate for physical educators to develop new ways to motivate their students to participate in class in order to help students develop physically active lifestyles outside of class.

Motivation in physical education classes can occur by appealing to student interests (Bycura \& Darst, 2001; Griffin \& Maina, 2002), allowing students to set and achieve goals (Bowyer, 1996; Bycura \& Darst, 2001), and particularly through allowing students to make choices in learning activities (Deci \& Ryan, 1987; Olafson, 2002; Prusak et al., 2004).

This review of literature provides evidence for the need of student choice in the physical education setting. Recent research indicates that student autonomy increases intrinsic motivation, thus increasing motivation to participate in a particular activity (Deci \& Ryan, 1987; Prusak et al., 2004). Will this increase in motivation cause students to put forth more effort leading to an increase in physical activity levels? This study will examine (a) the effects of increased autonomy on self-determination, and (b) the effects of increased autonomy on physical activity levels. 
Chapter 3

\section{Methods}

The purpose of this study is to examine (a) the effects of increased autonomy on self-determination, and (b) the effects of increased autonomy on physical activity levels. Participants

Four combined seventh-grade and eighth-grade female classes will be selected from a middle school with an average enrollment of 32.8 students per class, 122 students total. An informed consent form will be given to all students, which will be signed by parents approving their child's participation. Confidentiality of participants will be achieved by using identification numbers instead of names. Approval to conduct the study will be obtained from the principal, school district, and the Institutional Review Board at Brigham Young University.

Instruments

Pedometer. A Walk4Life MLS 2015 (Walk4Life, Plainfield, Illinois) pedometer will be used to measure step counts (an indicator of physical activity levels) of every student in each class. The dependent variable will be the mean number of steps over a seven-day fitness unit. The independent variable will be the level of autonomy (choice or no choice). Step counts will be recorded daily at the end of each class period. Individual student pedometer step counts will be averaged at the conclusion of each seven-day fitness unit and class means will be computed for a comparison between the two treatment models (seven days of choice, and seven days of no choice). 
Walk4Life pedometers have been tested for objectivity, reliability, and validity. Specifically, the Walk4Life LS 2525 model was tested for accuracy, and proved to be accurate within $\pm 1 \%$ of actual steps taken (Crouter, Schneider, Karabulut, \& Basset, Jr., 2003). A later study measured the accuracy of the same model, and found the Walk4Life LS 2525 pedometer to be moderately accurate within $\pm 20 \%$ of the correct number of steps 95\% of the time (Schneider, Crouter, Lukajic, \& Basset, Jr., 2003). Although pedometers are only sensitive to locomotor forms of movement, and they are not able to record the magnitude of movement, many tests have shown that pedometers are valid assessments of total volume of physical activity performed by children (Trost, 2001).

Situational Motivation Scale (SIMS). The 14-item SIMS (see full scale in Guay, Vallerand, \& Blanchard, 2000; see abridged scale in Standage, Treasure, Duda, \& Prusak, 2003) will be used to evaluate students' situational motivation across groups (see Appendix A-2). The SIMS has shown to be a valid and reliable tool for measuring selfdetermination index on many accounts (factorial validity, internal consistency, and multigroup invariance), and in many physical activity contexts (Standage et al., 2003). The SIMS will be administered four times, pre and post the first seven-day unit, and pre and post the second seven-day unit. Participants will respond to the stem question, "Why have you been participating in these specific activities (rope jumping, aerobics, kickboxing, etc.) over the past seven days? Items will be rated on a 7-point Likert scale ranging from 1 "corresponds not at all” to 7 "corresponds exactly."

The independent variable will be the level of autonomy (choice or no choice). The dependent variables will be represented in four subscale scores derived from the 14-item 
SIMS (Guay et al., 2000; Standage et al., 2003). The four subscales assess (a) intrinsic motivation (4 items), (b) identified regulation (3 items), (c) external regulation (3 items), and (d) amotivation (4 items).

Data will be reduced by (a) calculating each subscale score via the mean of its items and (b) further reduction by calculating the self-determination index (SDI) score via the following formula: (SDI $=+2$ (intrinsic motivation $)+1($ identified regulation $)-$ 1(external regulation) -2(amotivation)). The SDI, representing the strength of one's selfdetermination, is a straightforward weighting — the higher the number the stronger the self-determination.

Sport Motivation Scale (SMS). The SMS is an English translation of the French motivation scale l'Echelle de Motivation vis-à-vis les Sports (EMS; Brière, Vallerand, Blais, \& Pelletier, 1995). Research (Pelletier, Fortier, Vallerand, Tuson, Brière, \& Blais, 1995) indicates that the SMS measures contextual motivation with adequate levels of construct validity, and internal consistency.

A 16-item, 4-factor abridged version (amotivation, external regulation, identified regulation, and intrinsic motivation to know) of the full SMS (see full scale in Pelletier et al., 1995; see abridged scale in Guay, Mageau, \& Vallerand, 2003) will be administered to students in physical education classes (see Appendix A-2). This model is recommended for use in the physical education setting for its brevity, which may invoke more thoughtful responses from the students (Prusak et al., in review).

Participants will respond to the stem question, "Why do you participate in physical education?” Items will be rated on a 7-point Likert scale ranging from 1 “does 
not describe me at all” to 7 “ describes me exactly.” Data reduction will follow the same procedure as for the SIMS.

Procedures

One month prior to the fitness unit, students will be administered the SMS to measure contextual motivation and to account for any motivational differences between classes before treatment is given. The four classes will be randomly assigned to two groups to determine the fitness unit they will participate in first (choice or no choice). Two weeks later, the first phase of manipulation will begin. The instructor will begin to prepare students for the fitness activities by introducing the concept of choice or no choice. When speaking to the choice groups, the instructor will make statements such as: In two weeks we will begin a cardiovascular fitness unit where you are going to make a lot of choices. You can choose what activity you participate in, you can choose how hard you are going to work, what goals you are aiming for, and even who you are going to participate with. You will never have to participate in an activity that you do not like because you get to make the choice.

However, when speaking to the no-choice groups, the instructor will make comments such as:

In two weeks we are going to begin a cardiovascular fitness unit that I am really excited about. It is going to be a lot of fun, and I am going to make a lot of decisions for you. I will assign you to a team that you get to work with everyday, so you will get to know each other really well. Then, I will assign each team to a different activity everyday. You will have the opportunity to participate in every 
activity that this unit offers, which is really exciting!

Continuing with phase one of manipulation, every student will be asked to keep feelings about the treatment confidential, avoiding contamination between the two groups, because they will have an opportunity to share those feelings pre and post each unit on the SIMS.

Two classes will participate in the choice cardiovascular fitness unit for the first seven days. Participation in a three-week volleyball unit will follow to relieve student burnout. Following the three-week interval, students will participate in the no choice fitness unit for seven days. The other two classes will have the no-choice treatment first, the new three-week instructional unit, followed by the choice treatment. The same physical education instructor will teach all four classes for the duration of the study.

During the instructional unit preceding the study, students will be oriented to the pedometers, given instructions for proper use, and will be allowed practice time with the pedometers before data collection begins. This process is valuable to the study procedurally as well as accounting for the possibility of reactivity, although previous research (Vincent \& Pangrazi, 2002) focused on this issue, and had shown that no reactivity occurred when elementary students were fully aware that they were being monitored.

Each class is 45 minutes long (35 minutes of instructional time or activity time, and 10 minutes of dressing time). Immediately after the students change, at the beginning of class they will get a pedometer out of a box just outside the locker room, and sit down for roll call in the gym. Warm-ups and stretches will begin five minutes after the tardy 
bell and will last five minutes. The students will reset pedometers simultaneously after warm-ups and directly before actual activity time begins. Ten minutes before class is over, students will record their own step counts on a chart provided for them, clear pedometer readings for the following period, return their pedometers to the box, and sit down in roll call for a five-minute fitness or nutrition lesson while stretching. Five minutes will remain to allow students to dress for their next class period.

Activities will include four high intensity activities: (a) jogging, (b) kickboxing, (c) aerobics, and (d) rope jumping. Three of the four activities (different combination each day) will be available on days 1, 3, 5, and 7 (see Tables 1 and 2). On days 2, 4, and 6 the students will participate in one of three moderately intense walking games (Prusak \& Darst, 2002) around the perimeter of the gym: (a) Social Brisk Walking - students can bring their own music or talk to friends, but they must continue walking at a brisk pace with good form, (b) “Add 'em Up” - playing cards are placed face down in a hula hoop, and students quickly pick one up each time they pass. The student with the most points after 20 minutes wins, and (c) “Every Which Way But Loose” - students walk the length of the gym, and perform locomotor skills such as skipping, hopping, and sliding across the width of the gym while focusing on good form. Before the fitness unit begins, the instructor will introduce these activities to the students. A handout and schedule will be given to each student explaining the activities (see Appendix A-1). This will familiarize the students with the unit, making it run more efficiently.

Phase two of manipulation will begin on the first day of the fitness unit. The instructor will continue with the aforementioned manipulation statements, appropriate to 
the group the class will be in, attempting to make the environment clear to every student. The instructor will give the students choices, or make the decisions for them. The instructor will continue to encourage students to keep feelings confidential, reminding them to share ideas on the survey at the end of the seven-day unit.

Prior to the first day of data collection, the instructor will divide each no-choice class into three teams. The students must remain in these teams for the duration of the seven-day unit. Everyday the instructor will assign each team to one of three activities offered that day (no choice schedule on Table 1), where they must remain for the entire 20 minutes of activity. Over the course of the seven days, each team will participate in all four high intensity, and all three moderate intensity activities.

Much like the no-choice group, the classes with choice will have the same three activities offered on the same days (choice schedule on Table 2). However, the choice group will not be divided into teams. Following warm-ups, the students will have the opportunity to choose what activity they will participate in, and which students they participate with. This will give each student in the choice group the opportunity to participate in one of the activities three times over the seven-day unit if they find they really enjoy that particular activity. However, if they do not like the activity they choose, they must still participate in that activity for the duration of the class period, but can choose a different activity for the next class period.

Phase three of manipulation will begin when the seven-day fitness unit is finished. Immediately following each seven-day unit, the SIMS will be administered to students in every class to evaluate their self-determination index. The teacher will give procedures 
for the SIMS, and will administer the survey. The teacher will tell the students that it is now time for them to share their personal feelings about the unit by answering the questions on the survey.

To determine whether or not students felt they had a choice in each fitness unit, a manipulation check will be given to the students, where they will respond to the question, "I feel as though I have been participating in a unit that offers choices” after each unit. Answers will be rated on the same 7-point Likert scale as the SIMS.

Design and Statistical Analysis

Cronbach's $\alpha$ will be used to assess internal consistency and reliability for each subscale for both the SMS and the SIMS. Pearson correlations will also be computed among the subscales to support the simplex pattern of both questionnaires. Groups will be coded 1 = no choice first and 2 = choice first. Between-group and within-group differences in SDI for the SIMS will be analyzed through a repeated measures ANOVA test. Independent $t$ tests will be used for further analysis of SDI. Between-group and within-group differences in SDI for the SMS will be analyzed through a one-way ANOVA test. A repeated measures ANOVA test will be used to determine significant differences in step counts between groups and across trials. To analyze the manipulation check, a paired samples $t$ test will be used. Alpha level will be set at $p<0.05$.

The 16-item abridged version of the SMS questionnaire will be reduced to 4 subscales (IM to know, IDR, ER, AM) by finding the average of each of the four respective items. Similarly, the 14 -item SIMS will be reduced to 4 subscales (IM, IDR, ER, AM) through averaging the 3 or 4 respective items to each subscale. The self- 
determination index (SDI) will be calculated by weighting the subscales (SDI $=+2$ (IM) + 1(IDR) - 1(ER) - 2(AM)). Class means for step counts over each seven-day unit will be calculated. 


\section{References}

Bowyer, G. R. (1996). Student perceptions of physical education. Journal of Physical Education, Recreation \& Dance, 67(1), 23-26.

Brière, N. M., Vallerand, R. J., Blais, M. R., \& Pelletier, L. G. (1995). Dèvelopement et validation d'une measure de motivation intrinsèque et extrinsèque et d'amotivation en contexte sportif: L'Echelle de Motivation vis-à-vis les Sports (EMS). [Development and validation of the French form of the Sport Motivation Scale]. International Journal of Sport Psychology, 26, 465-489.

Bycura, D., \& Darst, P. W. (2001). Motivating middle school students: A health-club approach. Journal of Physical Education, Recreation \& Dance, 72(7), 24-29.

Crouter, S. E., Schneider, P. L., Karabulut, M., \& Basset, D. R. Jr., (2003). Validity of 10 electronic pedometers for measuring steps distance, and energy cost. Medicine and Science in Sports and Exercise, 35(8), 1455-1460.

Deci, E. L., \& Ryan, R. M. (1985). Intrinsic motivation and self-determination in human behavior (2nd ed.). New York: Plenum Press.

Deci, E. L., \& Ryan, R. M. (1987). The support of autonomy and the control of behavior. Journal of Personality and Social Psychology, 53(6), 1024-1037.

Griffin, M. R., \& Maina, M. P. (2002). Focus on interest diversity in high school physical education. Strategies, 15(6), 11-12.

Grolnick, W. S., \& Ryan, R. M. (1987). Autonomy in children’s learning: An experimental and individual difference investigation. Journal of Personality and Social Psychology, 52, 890-898. 
Guay, F., Mageau, G. A., \& Vallerand, R. J. (2003). On the hierarchical structure of selfdetermined motivation: A test of top-down, bottom-up, reciprocal, and horizontal effects. Personality and Social Psychology Bulletin, 29, 992-1004.

Guay, F., Vallerand, R. J., \& Blanchard, C. (2000). On the assessment of state intrinsic and extrinsic motivation: The situational motivation scale (SIMS). Motivation and Emotion, 24, 175-213.

Howard, B. K., \& Howard, M. R. (1997). What a difference a choice makes! Strategies, 10(3), 16-20.

Miserandino, M. (1996). Children who do well in school: Individual differences in perceived competence and autonomy in above average children. Journal of Educational Psychology, 88, 203-214.

Mokdad, A. H., Serdula, M. K., Dietz, W. H., Bowman, V. A., Marks, J. S., \& Koplan, J. P. (1999). The spread of the obesity epidemic in the United States, 1991-1998. Journal of the American Medical Association, 282, 1519-1522.

Olafson, L. (2002). “I hate phys. ed.”: Adolescent girls talk about physical education. The Physical Educator, 67-74.

Pangrazi, R. P. (2001). Dynamic physical education for elementary school children (13th ed.). Needham Heights, MA: Allyn \& Bacon.

Pelletier, L. G., Fortier, M. S., Vallerand, R. J., Tuson, K. M., Brière, N. M., \& Blais, M. R. (1995). Towards a new measure of intrinsic motivation, extrinsic motivation, and amotivation in sports: The Sport Motivation Scale. Journal of Sport \& Exercise Psychology, 17, 35-53. 
Pi-Sunyer, F. X. (1999). Comorbidities of overweight and obesity: Current evidence and research issues. Medicine and Science in Sports and Exercise, 31, S602-S608.

Prusak, K. A., Christensen, W., Standage, M., \& Treasure, D. (in review). The Sport Motivation Scale in physical education: A confirmatory factor analysis.

Prusak, K. A., \& Darst, P. W. (2002). Effects of types of walking activities on actual choices by adolescent female physical education students. Journal of Teaching in Physical Education, 21, 230-241.

Prusak, K. A., Treasure, D. C., Darst, P. W., \& Pangrazi, R. (2004). The effects of choice on the motivation of adolescent girls in physical education. Journal of Teaching in Physical Education, 23, 19-29.

Sallis, J., \& McKenzie, T. L. (1991). Physical education’s role in public health. Research Quarterly for Exercise and Sport, 62, 124-137.

Schneider, P. L., Crouter, S. E., Lukajic, O., \& Basset, D. R. Jr., (2003). Accuracy and reliability of ten pedometers for measuring steps over a 400-m walk. Medicine and Science in Sports and Exercise, 35(10), 1179-1784.

Shephard, R. J. (1995). Physical activity, fitness, and health: The current consensus. Quest, 47, 288-303.

Standage, M., Treasure, D. C., Duda, J. L., \& Prusak, K. A. (2003). Validity, reliability, and invariance of the situational motivation scale (SIMS) across diverse physical activity contexts. Journal of Sport \& Exercise Psychology, 25, 19-43. 
Thompson, C. E., \& Wankel, L. M. (1980). The effects of perceived activity choice upon frequency of exercise behavior. Journal of Applied Social Psychology, 10(5), 436-443.

Trost, S. G. (2001). Objective measurement of physical activity in youth: Current issues, future directions. Exercise and Sport Sciences Reviews, 29(1), 32-36.

Tudor-Locke, C. (2002). Taking steps toward increased physical activity: Using pedometers to measure and motivate. [Electronic version]. President's Council on Physical Fitness and Sports Research Digest, 3(17), 1-10. http://fitness. gov/Reading_Room/ Digests/digests.html

U.S. Department of Health and Human Services. (2000). Healthy People 2010: Understanding and Improving Health. 2nd ed. Washington, D.C: U.S. Government Printing Office.

U.S. Department of Health and Human Services. (1996). Physical Activity and Health: A Report of the Surgeon General, U.S. Department of Health and Human Services, Centers for Disease Control and Prevention, National Center for Chronic Disease Prevention and Health Promotion, Atlanta, GA.

Vallerand, R. J. (1997). Toward a hierarchical model of intrinsic and extrinsic motivation. In M. P. Zanna (Ed.), Advances in experimental social psychology: Vol 29 (pp. 271-360). New York: Academic Press.

Vallerand, R. J., (2001). A hierarchical model of intrinsic and extrinsic motivation in sport and exercise. In G. C. Roberts (Ed.), Advances in motivation in sport and exercise (pp. 263-319). Champaign, IL: Human Kinetics. 
Vincent, S. D., \& Pangrazi, R. P. (2002). Does reactivity exist in children when measuring activity levels with pedometers? Pediatric Exercise Science, 14(1), 56-63.

Welk, G. J., \& Blair, S. N. (2000). Physical activity protects against the health risks of obesity. [Electronic version]. President's Council on Physical Fitness and Sports Research Digest, 3(12), 1-10. http://fitness.gov/Reading_Room/ Digests/digests.html.

Whitehead, J. R. (1999). Physical activity and intrinsic motivation. Toward a Better Understanding of Physical Fitness and Activity, 1(2), 33-40.

Wright, M. T., Patterson, D. L., \& Cardinal, B. J. (2000). Increasing children’s physical activity. Journal of Physical Education, Recreation \& Dance, 71(1), 26-29. 
Table 1

Schedule of Activities for the No-Choice Group

\begin{tabular}{llll}
\hline Day & Team 1 & Team 2 & Team 3 \\
\hline 1 & Jogging & Kickboxing & Aerobics \\
2 & Walking Game 1 & Walking Game 2 & Walking Game 3 \\
3 & Kickboxing & Aerobics & Rope Jumping \\
4 & Walking Game 2 & Walking Game 3 & Walking Game 1 \\
5 & Aerobics & Rope Jumping & Jogging \\
7 & Walking Game 3 & Walking Game 1 & Walking Game 2 \\
\hline
\end{tabular}

Note. Walking game options are: (1) Social Brisk Walking, (2) “Add 'em Up”, and (3)

“Every Which Way But Loose” (Prusak \& Darst, 2002). Aerobics and Kickboxing activities are taught through video instruction. 
Table 2

Schedule of Activities for the Choice Group

\begin{tabular}{clll}
\hline Day & Option 1 & Option 2 & Option 3 \\
\hline 1 & Jogging & Kickboxing & Aerobics \\
2 & Walking Game 1 & Walking Game 2 & Walking Game 3 \\
3 & Kickboxing & Aerobics & Rope Jumping \\
4 & Walking Game 2 & Walking Game 3 & Walking Game 1 \\
5 & Aerobics & Rope Jumping & Jogging \\
7 & Walking Game 3 & Walking Game 1 & Walking Game 2 \\
\hline
\end{tabular}

Note. Walking game options are: (1) Social Brisk Walking, (2) “Add ‘em Up”, and (3) "Every Which Way But Loose” (Prusak \& Darst, 2002). Aerobics and Kickboxing activities are taught through video instruction. 
Appendix A-1

Student Handout and Schedule 


\section{DESCRIPTION OF FITNESS UNIT ACTIVITIES}

Directions: Three of these activities will be available everyday. Once you begin your workout, you must remain at the activity for the remainder of the class period (twenty minutes). New activities will be available to you the following day.

Jogging - Jog around the perimeter of the gym

Kickboxing - An instructional video (“Tae Bo”) combining music to martial arts-type movements.

Aerobics - An instructional video featuring your teacher. (Dance-like cardiovascular activity)

Rope Jumping - Listen to music and practice a variety of rope jumping skills on personal jumpropes and long jumpropes

Walking Game 1 - Social Brisk Walking - bring their own music or talk to friends, but you must continue walking at a brisk pace with good form around the perimeter of the gym.

Walking Game 2 - "Add 'em Up” - walking around the perimeter of the gym. Playing cards are placed face down in a hula hoop, and students quickly pick one up each time they pass by the hula hoop. The student with the most points after 20 minutes wins!

Walking Game 3 - "Every Which Way But Loose" - students walk the length of the gym, and perform locomotor skills such as skipping, hopping, and sliding at the ends of the gym. Focus is on form.

\begin{tabular}{|c|c|c|c|}
\hline Day & Activity 1 & Activity 2 & Activity 3 \\
\hline $\mathbf{1}$ & Jogging & Kickboxing & Aerobics \\
\hline $\mathbf{2}$ & Walking Game 1 & Walking Game 2 & Walking Game 3 \\
\hline $\mathbf{3}$ & Kickboxing & Aerobics & Rope Jumping \\
\hline $\mathbf{4}$ & Walking Game 2 & Walking Game 3 & Walking Game 1 \\
\hline $\mathbf{5}$ & Aerobics & Rope Jumping & Jogging \\
\hline $\mathbf{6}$ & Walking Game 3 & Walking Game 1 & Walking Game 2 \\
\hline $\mathbf{7}$ & Rope Jumping & Jogging & Kickboxing \\
\hline
\end{tabular}


Appendix A-2

Informed Consent and Surveys 


\section{Consent to be a Research Participant}

Dear Parent/Guardian,

Adolescent participation in physical activity continues to decline every year. A possible reason for this decrease in physical activity among youth may be due to a lack of motivation. I am conducting a research study to determine a way to increase student motivation, thus leading to higher activity levels. Your daughter has been requested to participate because she is currently enrolled in my physical education class.

In this study, your daughter will be administered a short questionnaire to measure her motivation towards physical education. One month later, participation in the study will involve wearing a pedometer (a device worn on the waistband, used to measure activity levels through vertical movement) for 14 class periods, taught in two seven-day units. Students will participate in a fitness unit that offers a variety of activities: jogging, aerobics, kickboxing, rope jumping, and walking. Your daughter will record her own step counts at the end of each class period. Immediately following both seven-day units, students will be administered a 14-item questionnaire to measure their motivational levels. Upon request, you are welcome to view a blank copy of the questionnaires.

This study presents no increased risks above those of normal classroom procedures. Direct benefits to participants may include greater physical activity levels. Possible benefits to society may include an increased understanding of how to motivate students to participate in physical education, thus helping instructors in their efforts to promote lifetime physical activity.

The results of this study may be published in a professional journal and/or presented at a professional conference. Your daughter's name will not be revealed, and will remain confidential through use of identification numbers. Participation in this study is voluntary. If you do not want your daughter to participate, or you choose to withdraw her participation at anytime it will not affect her grade or school standing in any way.

If you have any questions regarding this study, call me at (801) 374-4970, or email me at jillwa@provo.edu. If you have questions you do not feel comfortable asking me, contact Dr. Carol Wilkinson, Associate Professor of Exercise Sciences at BYU, (801) 422-8779, 249 D SFH, carol_wilkinson@byu.edu. If you have any questions regarding your daughter's rights as a participant in this research project, you may contact Dr. Renea Beckstrand, IRB Chair, (801) 4223873, 422 SWKT, renea_beckstrand@byu.edu.

Sincerely,

Jillian Ward

(Please initial) page 1 of 2

See next page 
Adolescent's name (please print): Grade Level:

My parent/guardian has given permission for me to take part in this research study. I understand that participation in this study will require me to wear a pedometer, a small electronic device worn on the waistband that measures vertical movement, and fill out a total of three motivational surveys. I will wear the pedometer every class period, and will use it properly. I agree to fill out surveys concerning my motivational disposition. I am participating in this study because I want to and I am aware that findings in this study may help others in the future. I understand that I may withdraw participation in this study at any time without being penalized.

Adolescent's signature

Date

Parent Consent

Please answer the following questions:

Adolescent's birthday:

month $\frac{1}{\text { day }} \frac{}{\text { year }}$

Adolescent's age:

Adolescent's Ethnicity (optional):

- African American

Hispanic

_ Native American

_ Pacific Island/ Asian

- White

I have read, understood, and received a copy of the consent form, and allow my daughter to participate in this research study. 
The 14-Item SIMS (Guay, et al., 2000; Standage et.al, 2003)

Directions: Read each item carefully. Using the scale below, please circle the number that best describes the reason why you are currently engaged in this activity.

Why have you been participating in these specific activities (rope jumping, aerobics, kickboxing, etc.) over the past seven days?

\begin{tabular}{|c|c|c|c|c|c|c|}
\hline 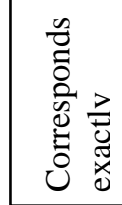 & 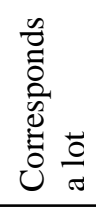 & 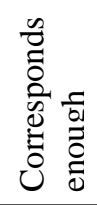 & 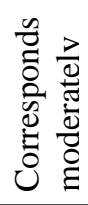 & 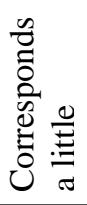 & 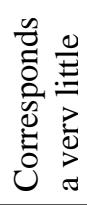 & 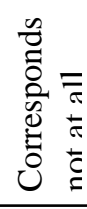 \\
\hline
\end{tabular}

1. Because I think that this activity is interesting.

$\begin{array}{lllllll}7 & 6 & 5 & 4 & 3 & 2 & 1\end{array}$

2. Because I am doing it for my own good.

7

(2)

3. Because I am supposed to do it.

$\begin{array}{lllllll}7 & 6 & 5 & 4 & 3 & 2 & 1\end{array}$

4. There may be good reasons to do this activity, but I don’t personally see any.

7

5. Because I think that this activity is pleasant.

7

6

54

$\begin{array}{ll}3-2 & 1\end{array}$

6. Because I think that this activity is good for me.

$\begin{array}{lllllll}7 & 6 & 5 & 4 & 3 & 2 & 1\end{array}$

7. Because it is something that I have to do.

$\begin{array}{lllllll}7 & 6 & 5 & 4 & 3 & 2 & 1\end{array}$




\begin{tabular}{|c|c|c|c|c|c|c|}
\hline 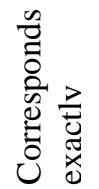 & 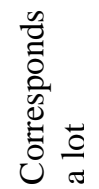 & 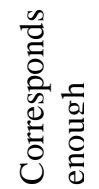 & 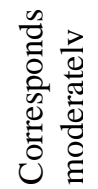 & 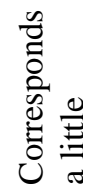 & 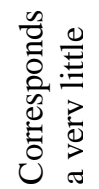 & 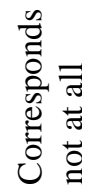 \\
\hline
\end{tabular}

8. I do this activity but I am not sure if it is worth it.

$\begin{array}{lll}7 & 6 & 5\end{array}$

$4 \quad 3 \quad 2$

1

9. Because this activity is fun. $\quad \begin{array}{llllllll}7 & 6 & 5 & 4 & 3 & 2 & 1\end{array}$

10. I don’t know; I don’t see what

$\begin{array}{lllllllll}\text { the activity brings me. } & 7 & 6 & 5 & 4 & 3 & 2 & 1\end{array}$

11. Because I feel good when

doing this activity.

7

$6 \quad 5$

5

$4 \quad 3 \quad 2$

1

12. Because I believe this activity

is important for me. $\quad \begin{array}{llllllll}7 & 6 & 5 & 4 & 3 & 2 & 1\end{array}$

13. Because I feel I have to do it. $\quad \begin{array}{llllllll}7 & 6 & 5 & 4 & 3 & 2 & 1\end{array}$

14. I do this activity, but I am not

sure it is a good thing to

\begin{tabular}{lllllllll} 
pursue it. & 7 & 6 & 5 & 4 & 3 & 2 & 1 \\
\hline
\end{tabular}

Directions: Using the same scale, please answer the following question:

1. I feel as though I have been

participating in a unit that

$\begin{array}{lllllllll}\text { offers choices. } & 7 & 6 & 5 & 4 & 3 & 2 & 1\end{array}$ 
THE SPORT MOTIVATION SCALE

\section{Directions: Read each item carefully. Using the scale below, please indicate how well the statement describes how you feel toward physical education.}

Why do you participate in physical education?

\begin{tabular}{|c|c|c|c|c|c|c|}
\hline $\begin{array}{c}\text { Does not } \\
\text { describe } \\
\text { me } \\
\text { at all }\end{array}$ & $\begin{array}{c}\text { Describes } \\
\text { describes } \\
\text { me exactly }\end{array}$ \\
\hline
\end{tabular}

1. For the pleasure it gives me to know more about exercise and being healthy.

$\begin{array}{lllllll}1 & 2 & 3 & 4 & 5 & 6 & 7\end{array}$

2. I used to have good reasons

for going to P.E., but now

I am asking myself if I should continue doing it.

3. For the pleasure of discovering new training techniques.

$\begin{array}{lllllll}1 & 2 & 3 & 4 & 5 & 6 & 7\end{array}$

4. I don't know anymore; I have the impression that I can't succeed in P.E.

1

5. Because it makes me look good in front of other people I know.

$\begin{array}{lllllll}2 & 3 & 4 & 5 & 6 & 7\end{array}$


6. Because in my opinion, it is one of the best ways to hang out with people.

12

3

$4 \quad 5$

$6 \quad 7$

7. For the prestige of being good in P.E. 12

$\begin{array}{lllll}3 & 4 & 5 & 6 & 7\end{array}$

8. Because it is one of the best one of the best ways to $\begin{array}{lllllllll}\text { develop other parts of myself. } & 1 & 2 & 3 & 4 & 5 & 6 & 7\end{array}$

9. Because people around me think $\begin{array}{lllllllll}\text { it is important to be in shape. } & 1 & 2 & 3 & 4 & 5 & 6 & 7\end{array}$

10. Because P.E. is a good way to learn lots of things which could be useful to me in other areas $\begin{array}{lllllllll}\text { of my life. } & 1 & 2 & 3 & 4 & 5 & 6 & 7\end{array}$

11. It is not clear to me anymore; I don’t really think I find success in P.E. $\begin{array}{lllllll}1 & 2 & 3 & 4 & 5 & 6 & 7\end{array}$

12. To show others how good I $\begin{array}{lllllllll}\text { am at the P.E. activities. } & 1 & 2 & 3 & 4 & 5 & 6 & 7\end{array}$

13. For the pleasure I feel while learning new exercises and skills in P.E. 1 $\begin{array}{lllll}3 & 4 & 5 & 6 & 7\end{array}$ 
14. Because it is a good way to

maintain good relationships

$\begin{array}{lllllllll}\text { with my friends. } & 1 & 2 & 3 & 4 & 5 & 6 & 7\end{array}$

15. For the pleasure of discovering

$\begin{array}{lllllllll}\text { new performance strategies. } & 1 & 2 & 3 & 4 & 5 & 6 & 7\end{array}$

16. I often ask myself; I can’t seem to

achieve the goals that I set for

$\begin{array}{llllllll}\text { myself in P.E. } & 1 & 2 & 3 & 4 & 5 & 6 & 7\end{array}$ 